\title{
Not rocket science
}

\author{
Patient Safety, 2nd Edition \\ Charles Vincent \\ John Wiley \& Sons; 2010.
}

\section{A} story is making the rounds that James Reason, (whose classic Human Error ${ }^{1}$ is one of the most widely cited references in medicine) was talking with someone outside of health care, about medical error. "How is it," they purportedly asked," that so many errors are made in medicine, I mean it's not rocket science, is it?" "No, it isn't," replied Reason, "it's more complicated."

The sobering message from Professor Charles Vincent in this second edition of Patient Safety, ${ }^{2}$ is that it is indeed a complicated business and there are few easy answers. It seems that no sooner does a bright idea to reduce the toll of medical error emerge, than its promise fades or fails. Why shouldn't we travel through the system as safely as if airborne, or move smoothly and efficiently as though on a Toyota production line? Part of the problem is that there is infinitely more variability in the human body than in airplanes and cars, a variability that leads to an irreducible uncertainty. Parallels with industries, states Vincent, are not always clear and their high-reliability practices should not be uncritically adopted. We should be a little more skeptical, he says, and mentions the reservations voiced about the true efficacy of the heavily promoted Safer Patients' Initiative to save 100000 lives campaign. ${ }^{3}$ One wonders, too, about the impact of such initiatives on other aspects of care. Resources are, after all, finite.

The Patient Safety Movement launched a little over a decade ago to what was described as the medical equivalent of a shot heard around the world. In the frenzy that followed, proponents and proselytizers have galloped off in all directions and much useful work has been done. In this second edition, as in the first in 2006, Vincent reins us in. He assesses where we are and from where we have come. His arguments and obser-

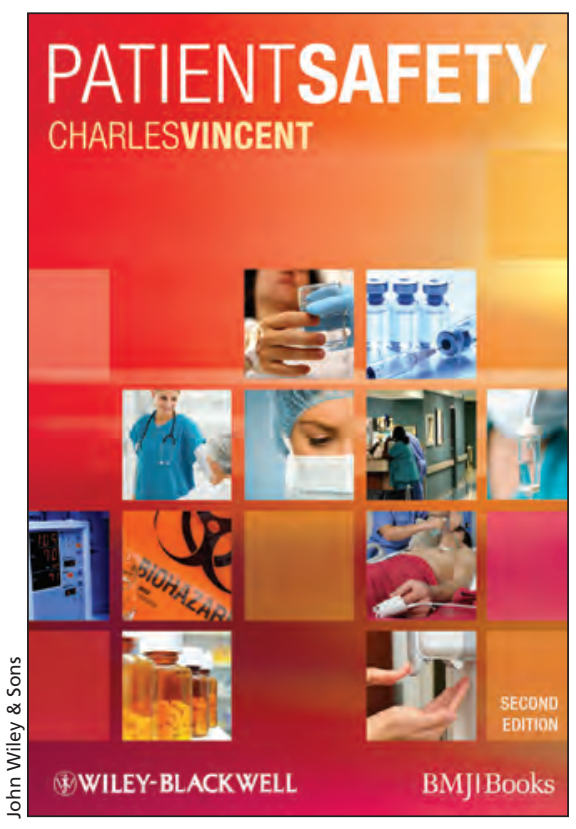

vations check and balance us without undue polarization. At over 400 pages, this second edition is nearly double the length of the first. Original material is expanded upon. As before, his chapter on "Caring for patients harmed by treatment" is outstanding in its depth and insights. Eight new chapters have been added covering topics such as measurement, designing for safety, specific safety skills, and high performing health care systems. Having suffered several times through tortuous explanations of "violations and migrations" without much enlightenment, I was relieved to find it framed in language I could understand. In addition to the new material, there is increased emphasis on crucial areas such as teamwork and patient involvement. In particular, clinical decision-making, arguably the one feature of a clinician's performance that has the most pervasive effect on patient safety, gets more consideration. In another recent book in this area, the number of cognitive biases is estimated to be in excess of $100 .{ }^{4}$ Not surprisingly, failed reasoning accounts for a significant proportion of the current estimated diagnostic error rate of about $15 \%$. Finally, it may be worth noting in passing that in a book on patient safety, a chapter on the insidious and not insignificant role played by the pharmaceutical industry in adverse events would be welcome.

Despite the expanded scope, the author has retained his refreshingly individual approach, thankfully sprinkled with flashes of English wit. In a discussion of hospital environments, for example, we should aim for "an ambience of monastic calm rather than a downtown bus station." It's remarkable the way he moves effortlessly across widely differing areas from safety issues in deep-sea fishing to that of British train shunters (who suffer an alarming mortality rate) pulling each vivid example into the context of health care.

Vincent, a psychologist, has proved to be a fortunate catch for medicine. Few others within the ever-blinkered silos would be able to achieve his broad perspective. In fact, the recent trend appears to be for specific disciplines to provide their own view of what patient safety means for them, and clearly they all have unique patient safety issues. The imperative remains, however, to keep the overall focus on the patient and the system in which they seek care, and that seems to require the services of an unblinkered outside observer.

\section{Pat Croskerry MD PhD}

Director, Critical Thinking Program

Division of Medical Education

Dalhousie University

Halifax, NS

A 60-page condensed version, Essentials of Patient Safety, is now available free online at www.wiley.com/go/vincent/patientsafety /essentials

\section{References}

1. Reason JT. Human error. New York (NY): Cambridge University Press; 1990.

2. Vincent C. Patient safety 2 nd ed. Chichester (UK): Wiley-Blackwell; 2010.

3. Wachter RM, Pronovost PJ. The 100,000 lives campaign: a scientific and policy review. Jt Comm J Qual Patient Saf 2006;32:621-7.

4. Jenicek M. Medical error and harm: understanding, prevention and control. New York (NY): Productivity Press; 2011.

CMAJ 2013. DOI:10.1503/cmaj.120541 